\title{
Material Performance Tests of the Polymer-Cement Thin Spray-On Liner
}

\author{
Qizheng Dong, ${ }^{1}$ Lianjun Chen $\mathbb{D}^{2,3,4}$ Weimin Cheng, ${ }^{2,3,4}$ Zhaoxia Liu, ${ }^{1,3}$ Xiangfei Cui $\mathbb{D},{ }^{2,3}$ \\ Guoming Liu, ${ }^{2,3}$ Zhiwei Shi, $^{2}$ Zhenjiao Sun, ${ }^{2}$ and Yaqing Zhang ${ }^{5}$ \\ ${ }^{1}$ College of energy and Mining Engineering, Shandong University of Science and Technology, Qingdao 266590, China \\ ${ }^{2}$ College of Safety and Environmental Engineering, Shandong University of Science and Technology, Qingdao 266590, China \\ ${ }^{3}$ State Key Laboratory of Mining Disaster Prevention and Control Co-founded by Shandong Province and Ministry of Science \\ and Technology, Shandong University of Science and Technology, Qingdao 266590, China \\ ${ }^{4}$ National Demonstration Center for Experimental Mining Engineering Education, Shandong University of Science and Technology, \\ Qingdao 266590, China \\ ${ }^{5}$ College of Chemical and Biomedical Engineering, Shandong University of Science and Technology, Qingdao, \\ Shandong 266590, China
}

Correspondence should be addressed to Lianjun Chen; skyskjxz@163.com and Xiangfei Cui; cuixf11@163.com

Received 23 October 2020; Revised 2 November 2020; Accepted 5 November 2020; Published 14 December 2020

Academic Editor: Bin Gong

Copyright (C) 2020 Qizheng Dong et al. This is an open access article distributed under the Creative Commons Attribution License, which permits unrestricted use, distribution, and reproduction in any medium, provided the original work is properly cited.

Compared to conventional shotcrete, thin spray-on liner (TSL) has several advantages, including high efficiency, good adhesion, and low dust content. In order to study the underlying mechanism of polymers on thin spray-on liner materials, three polymers were tested in this study. They were mixed into the shotcrete materials to conduct viscosity, pulling, flexural strength, and compression tests. The correlations between the viscosity of the materials and their other mechanical properties were analyzed. The optimal mixing ratio obtained by the tests was at a polymer-cement ratio of $15 \%$. The material had better mechanical properties overall when modified with a vinyl acetate-ethylene (VAE) copolymer emulsion. When a VAE emulsion was used to modify cement mortar, the results showed that the VAE modified mortar had the best viscosity performance of any of the tested emulsions at the same polymer-cement ratio. Because of the adhesion of the modified mortar on a marble wall, when the viscosity was 2,300-5,800 $\mathrm{mPa} \cdot \mathrm{s}$, the slurry was evenly distributed and did not sag on the wall surface. The VAE emulsion was affected by its own viscosity, and the pull-out strength was also enhanced as the viscosity increased. As the viscosity of the VAE emulsion increased, its flexural strength initially increased and then decreased, whereas its compressive strength decreased linearly. This study provides a theoretical basis for the development and application of thin shotcrete materials.

\section{Introduction}

A layer of traditional shotcrete needs a certain thickness to produce a supporting strength. Through a combination of basic mechanical tests and dynamic and static load tests, it has been found that traditional sprayed concrete can have shortcomings in ductility and sprayability [1-5]. Additionally, a large amount of dust can be easily generated on the spraying surface, which endangers the health of workers [6-11]. European and American researchers have proposed a thin spray-on liner (TSL) sealing and support technology [12]. This is a new support concept. TSL is usually defined as a reactive or nonreactive multicomponent material containing cement, latex, or polymer [13]. A TSL is used to cover a roadway with a very thin spray layer to provide load-bearing and sealing functions. The TSL is a surface-supporting sealing material used in mining and civil engineering. In the preparation process of thin spray material, the filler is mostly fine aggregate, and the slurry of thin spraying material is nonNewtonian fluid, which has good pore permeability. By using the complementary capabilities of thin spraying and shotcrete, the effects of sealing and supporting the working surface can be achieved. 
Ohama and Konietzko [14, 15], respectively, proposed the mechanism of polymer-modified cement mortar. The starting points of these two mechanism models are the same. They are both from the polymer emulsion film, particles, and gels produced by cement hydration. To study the mechanism of polymer-modified cement, the Ohma structure model believes that the hardened cement paste is wrapped in the polymer membrane, but the Konietzko structure model believes that the cement paste and the polymer penetrate each other. A spatial three-dimensional network structure is formed. The key point in the field of TSL material research is the use of polymer emulsions with a combination of necessary properties. The polymer emulsion must be highly compatible with the cement, such that the cement can be homogeneously mixed with the emulsion and will not precipitate mixing. Also, the emulsion must have a delayed hydration effect on the cement so that it provides sufficient time for spraying during construction. Finally, the film formed with the cement must have good mechanical properties to resist changes in external stress. The polymer emulsions, which are currently used, are vinyl acetate-ethylene (VAE) copolymer emulsions, pure acrylic emulsions, styrene-acrylic emulsion, fluoropropylene emulsions, and other polymer-modified emulsions.

Among others, Burea et al. [16] studied the effect of styrene-butadiene emulsions on the mechanical properties of cement mortar. When the water-cement ratio was 0.45 and the polymer-cement ratio was $7.5 \%$, the flexural strength of the samples reached its maximum. As the polymer concentration continued to increase, the flexural strength decreased accordingly. Li et al. [17] compared ordinary cement mortar with and without the addition of a pure acrylic emulsion and found the compressive strength was reduced by $24 \%$, while the tensile strength and tensile bond strength increased by 28 and $268 \%$, respectively. In addition, frost resistance, alkali resistance, and impermeability were significantly improved. Xu et al. [18] studied the effect of different concentrations of VAE emulsion on the flexural strength of cement mortar. Their results showed that the flexural strength of VAE emulsion-modified cement mortar was significantly improved when the emulsion concentration was $4-5 \%$.

Due to the laboratory research and field tests from many researchers, the physicochemical properties and mechanism of TSL have been well-described. According to the literature, Ozturk et al. [19] used 13 different performance testing apparatus, wherein the compression test of the coating core layer was the best choice for the evaluation of the mechanical properties of a TSL. The main purpose of the coating core test is to simulate the mechanical performance of the TSL on the base material. This test method was originally proposed by Espley et al. [20]. After this study, other researchers have conducted the same test to understand the supporting mechanism on the working surface when using a TSL as the base material [21-26]. Qiao et al. [26] demonstrated a significant improvement of the uniaxial compressive strength for coatings with TSL base materials. Yilmaz et al. [27] studied TSL samples produced by different factories and enterprises and prepared specimens to examine the tensile strength of the
TSLs, compared with that of sprayed shotcrete. The results showed that the tensile strengths of more than $50 \%$ of the common TSLs were above $4 \mathrm{MPa}$, their compressive strengths were in the range of $0.5-7.8 \mathrm{MPa}$, and the sample made with the sprayed shotcrete had the lowest tensile strength $(0.5 \mathrm{MPa})$. Son et al. [28] examined the adhesive strength of sprayed shotcrete on a rock surface. The results from the direct method using splitting had an average value of $0.81 \mathrm{MPa}$, while the results from indirect method using a flexural tensile test had an average value of $2.35 \mathrm{MPa}$. Ozturk et al. [29] found that a TSL had different adhesive strengths on different base materials, such as sandstone, granite, and paving stones, which were $11.4,0.4$, and $3.7 \mathrm{MPa}$, respectively. These values were higher than the adhesive strength of materials made from the sprayed concrete technique and the base material. The above research results were mostly limited to a single mechanical performance test of the TSL materials. They have not yet reported on a variety of mechanical tests and performance analysis.

A review of the literature found that the VAE, pure acrylic, and styrene-acrylic emulsions have good mechanical properties. In addition, the above three polymer emulsions are mostly used in the modification of ordinary cement mortar. The modified cement mortar has enhanced mechanical properties. In the published reports, many different test methods have been used for investigations of the mechanical properties of TSLs, but most of the reports only used one of the test methods for their analyses. Here, we used these three polymer emulsions as modified polymers for TSL materials and analyzed a variety of different mechanical properties. We tested and summarized various characteristics to obtain the most suitable polymer emulsion and concentration for the TSL material. Considering the difficulty of TSL onsite preparation and the toxicity of the polymer material itself, this article chose to prepare nonreactive TSL materials. By using simulation analyses on different data from various mechanical tests, we obtained a quantitative relationship between the viscosity of different polymer-modified cement mortars and the pull-out strength, flexural strength, and compressive strength, as well as analyzed the causes for variations in these properties. This report provides the relevant theoretical data for material selection and preparation of nonreactive thin spray materials and accelerates their development and practical application.

\section{Materials and Methods}

\subsection{Raw Materials}

2.1.1. Cement. PO 42.5 cement: in order to achieve economic application of the materials, more extensive area coverage, and a high bond strength of the formulated spray, PO 42.5 ordinary Portland cement was used. The chemical composition is shown in Table 1, including material composition characteristics from the manufacturers.

2.1.2. Filler. Light calcium carbonate: a tasteless and odorless white solid. Calcium carbonate was used as a mineral filler 
TABle 1: Cement chemical composition table.

\begin{tabular}{lcccccc}
\hline Raw materials & $\mathrm{SiO}_{2}$ & $\mathrm{AI}_{2} \mathrm{O}_{3}$ & $\mathrm{Fe}_{2} \mathrm{O}_{3}$ & $\mathrm{CaO}$ & $\mathrm{MgO}$ & $\mathrm{SO}_{3}$ \\
\hline Percentage (\%) & 19.5 & 6.45 & 3.08 & 57.57 & 1.21 & 2.01 \\
\hline
\end{tabular}

material with the thin spray powder after adding water. It can improve the adhesion of the spray. The chemical composition is shown in Table 2.

2.1.3. Additives. Cement quick-setting agent: used to accelerate the hydration and hardening of the polymer-modified cement. It can form sufficient strength in a short period of time to ensure it meets the working requirements for spraying cement.

Polycarboxylic acid series high performance water reducing agent: due to the dispersion of cement particles, adding a water reducing agent can improve its workability, reduce the unit water consumption, and improve the fluidity of the mixture. The water reducing agent can also reduce the amount of cement per unit and the total consumption of cement.

Dodecanol ester film-forming agent: it can effectively reduce the minimum film-forming temperature, and it is generally used in latex. It is used because many polymers used in latex paints cannot form films at room temperature. For the latex paint to form a complete film, a film-forming aid agent that acts as a coalescent must be added.

Polydimethylsiloxane defoamer: due to the influence of surfactants, such as emulsifiers and stabilizers, in the emulsion, many small bubbles are usually generated in the concrete. These small bubbles are eliminated by the defoamer to reduce the porosity, and to ensure the strength is stable.

Cellulose: it plays a role in slurry thickening and water retention. The specific characteristics of each material are shown in Table 3.

2.1.4. Polymer Emulsion. VAE emulsion: a material based on the copolymerization of vinyl acetate and vinyl monomer. It is a high molecular weight emulsion, which is copolymerized by adding emulsifier and initiator to the monomers in a highpressure emulsion polymerization.

Styrene-butadiene emulsion: the styrene-butadiene emulsion is derived from the copolymerization of styrene and butadiene. The heat resistance of the styrene-butadiene latex emulsion is superior to that of the styrene-butadiene rubber emulsion.

Pure acrylic emulsion: it has fine particle size, high gloss, excellent weather resistance, excellent antistickiness, and wide applicability. The specific characteristics of each material are shown in Table 4.

\subsection{Test Method}

2.2.1. Preparation of Materials. The composition of the TSL material is shown in Table 5 . The polymer emulsion with a polymer-cement ratio of $5-20 \%$ had better mechanical properties [30-32]. Therefore, in order to screen the most suitable polymer emulsion for the TSL material and the mixing ratio, we evaluated polymer-cement ratios of $5,10,15$, and $20 \%$. In the water-cement ratio, we fixed the water-cement ratio of all the polymer-modified cement mortars to 50\% [32] and also fixed the ratios for cellulose, accelerator, water reducer, defoamer, and film-forming agent [30, 31, 33]. The filler had a fixed ratio of $5 \%$ calcium carbonate [33].

Because the polymer exists in the form of an emulsion, when calculating its concentration, the mass of the emulsion is multiplied by its solid content ratio, and the remaining mass is calculated, depending on the amount of added water. Therefore, the water quality calculated by the water-cement ratio includes the mass of water in the emulsion and the quality of the added water.

There are three steps to preparing TSL materials:

(1) Dissolve the cellulose and polymer emulsion in water to reduce the air bubbles entering the system. Then, add the defoamer and stir. Finally, add a filmforming agent. Use a hand mixer to mix at low speed for 2-3 min. The polymer emulsion and auxiliary components are thoroughly mixed in water

(2) Thoroughly mix the two types of cement powders and calcium carbonate to disperse the two powders

(3) Pour the powder from step (2) into the liquid from step (1) and mix. Use a hand-held mixer to stir at low speed for $1 \mathrm{~min}$, and then add the quick-setting agent and water reducer, and continue to stir for $3 \mathrm{~min}$. After fully mixed, the TSL material is quickly placed in each set of experimental molds

2.2.2. Viscosity Test. We used a rotational viscometer (NDJ79) for the viscosity measurements of the TSL slurry and used a spray gun to spray the marble surfaces. We also combined the viscosity data and the distribution of the slurry on the wall surface of the spray layer to perform a basic flow performance analysis with the different TSL slurries. Through the preliminary preparation test, the spray condition parameters with a wind pressure of $0.4 \mathrm{Mpa}$ and a spray distance of $0.4 \mathrm{~m}$ will be tested.

Procedure: first, prepare the TSL material with a composition shown in Table 5 . Carefully pour a portion of the slurry into the test container until the surface reaches a lower tapered edge and then insert the drum into the liquid until completely immersed. Place the test container on the instrument bracket, hang the drum hook, adjust zero, and start the instrument.

Another portion of the TSL slurry is poured into the gun within the sprinkler using a pressure of $0.4 \mathrm{MPa}$. A spray gun is used to spray the marble surface. See Figure 1(b).

2.2.3. Pull Test. Procedures: first, use a mold to prepare a $5 \mathrm{~mm}$ thick [34] TSL material pull-out specimen on the base surface of the marble. After the preparation of the sample is completed, the free end of the screw is snapped into the pull-out unit. Make sure that the central axis of the screw and the central axis of the pull-out unit are aligned on the same line. Minimize the influence of the eccentric load and the bending moment. Then, rotate the handle at a constant speed to pull the TSL material attached to the pull-off unit away from the surface of the substrate until it is completely 
TABLE 2: Chemical composition of light calcium carbonate.

\begin{tabular}{lcccccc}
\hline Raw materials & $\mathrm{CaCO}_{3}$ & $\mathrm{SiO}_{2}$ & $\mathrm{AL}_{2} \mathrm{O}_{3}$ & $\mathrm{Fe}_{2} \mathrm{O}_{3}$ & $\mathrm{Na}_{2} \mathrm{O}$ & Density \\
\hline Percentage (\%) & $97.1 \%$ & $0.63 \%$ & $0.22 \%$ & $0.11 \%$ & $0.03 \%$ & $2.71 \mathrm{~g} / \mathrm{cm}^{3}$ \\
\hline
\end{tabular}

TABLE 3: Admixture characteristic ingredient list.

\begin{tabular}{|c|c|c|c|c|c|}
\hline Additives & Main ingredient & Color & Solid content $(\%)$ & $\mathrm{pH}$ & Feature \\
\hline Cement quick-setting agent & $\begin{array}{l}\text { Calcium aluminate, sodium } \\
\text { aluminate and sodium carbonate }\end{array}$ & White & - & - & Powdery solid \\
\hline $\begin{array}{l}\text { Polycarboxylic acid series high } \\
\text { performance water reducing agent }\end{array}$ & Polycarboxylate & White & - & $7-9$ & Powdery solid \\
\hline Dodecanol ester film-forming agent & Dodecyl alcohol ester & Colorless and transparent & $40 \%$ & 6 & Liquid \\
\hline Polydimethylsiloxane defoamer & Polydimethylsiloxane & Colorless or light yellow & $60 \%$ & $5-8$ & Liquid \\
\hline Cellulose & Cellulose & White & - & - & Powdery solid \\
\hline
\end{tabular}

Table 4: Polymer emulsion composition characteristic table.

\begin{tabular}{|c|c|c|c|c|c|}
\hline Polymer emulsion & Main ingredient & Color & Solid content (\%) & $\mathrm{pH}$ & Feature \\
\hline VAE emulsion & Vinyl acetate-ethylene copolymer & Milky & $40 \%$ & $4-5.5$ & Liquid \\
\hline Styrene-butadiene emulsion & Butadiene-styrene copolymer & White & $40 \%$ & $7-8$ & Liquid \\
\hline Pure acrylic emulsion & Various acrylic, methacrylic, and methyl methacrylate & White & $40 \%$ & $7.5-9$ & Liquid \\
\hline
\end{tabular}

separated. The peak value of this process is displayed on the instrument display, which is the bond strength of the material, as shown in Figures 2 and 3.

2.2.4. Flexural Test. Procedure: make the TSL slurry according to the mixing ratio in Table 5. After stirring evenly, install the mold on the triple test mold and remove bubbles by vibration. Make labels after $12 \mathrm{~h}$ and remove the mold for maintenance after $24 \mathrm{~h}$. After the specimen is hardened and demolded in the triple test mode, it is placed in the air at room temperature and maintained for $28 \mathrm{~d}$ [35]. Place the produced mold on the antibending fixture and control the electro-hydraulic servo universal tester through the microcomputer. Increase the load uniformly at a rate of $2400 \pm$ $200 \mathrm{~N} / \mathrm{s}$ and conduct the flexural test.

2.2.5. Compression Test. The equipment used in the compression test is different from the compression fixture (see Figure 4). The rest of the equipment is the same as the flexural strength test, and the preparation of samples and procedures are also the same (see Section 2.2.4 for details).

\section{Results and Analysis}

3.1. Viscosity Test Analysis. As shown in the mix ratio of TSL materials in Table 5 we used three polymer emulsions with different polymer-cement ratios and measured their viscosity with an NDJ-79 rotary viscometer. After obtaining the data, formula (1) was used to calculate the viscosity, $\eta$,

$$
\eta=k a
$$

where $k$ is a coefficient (a rotor with a coefficient of 100 is selected in this test) and $a$ is the deflection angle of the pointer. The results are shown in Figure 5 and can be summarized as follows.

(1) The viscosity of the VAE emulsion increased with the increase of the polymer-cement ratio, and the viscosity growth rate was faster. The increase rates for the samples with polymer-cement ratios of 10,15 , and $20 \%$ were 60,56 , and $29 \%$, respectively. The maximum viscosity appears in the $20 \%$ VAE emulsion, which was $7500 \mathrm{mPa} \cdot \mathrm{s}$

(2) The viscosity of the pure acrylic emulsion also increased as the polymer-cement ratio increased, and the viscosity growth rate was slower. The increase rates for the samples with polymer-cement ratios of 10,15 , and $20 \%$ were 33,10 , and $13 \%$, respectively

(3) The viscosity of the styrene-butadiene emulsion gradually decreased with increasing polymer-cement ratio, and the minimum viscosity (1700 $\mathrm{mPa} \cdot \mathrm{s})$ appeared in the $20 \%$ styrene-butadiene emulsion

Because the three polymer emulsions had the same solid content, when the polymer content of the polymer emulsion was the same, the total specific surface area of the particles in the emulsion became larger. This enhanced the interaction and motion resistance between the particles, resulting in an increase of the viscosity of the polymer emulsion.

The test slurries, with the different ratios of TSL materials shown in Table 5, were sprayed on the marble surface with a 


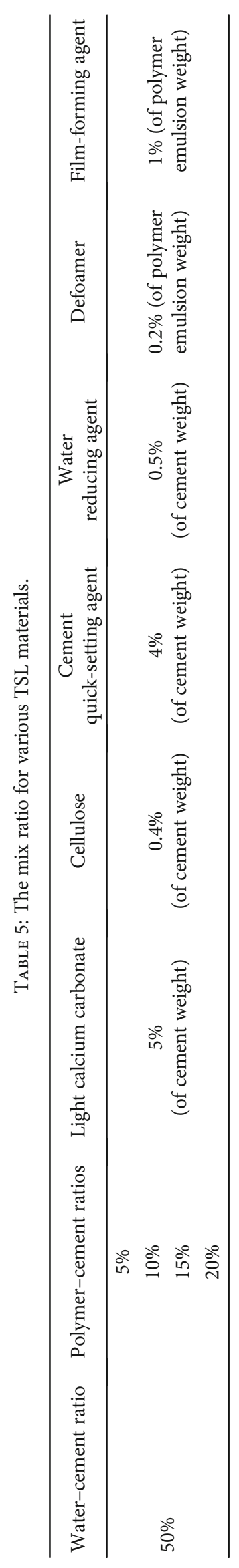




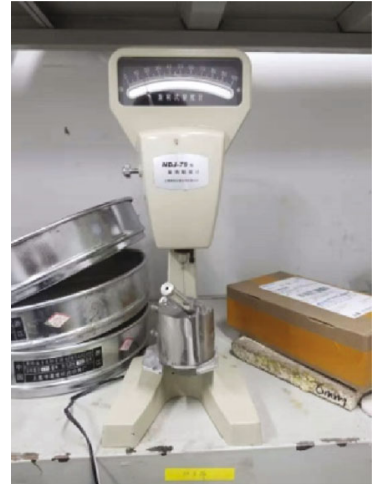

(a) Viscosity test

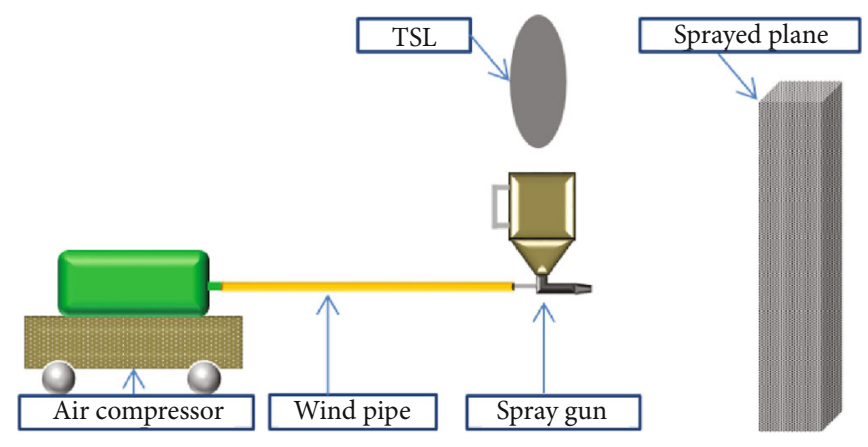

(b) Spray TSL material

FIgURe 1: Viscosity test and spray TSL material.

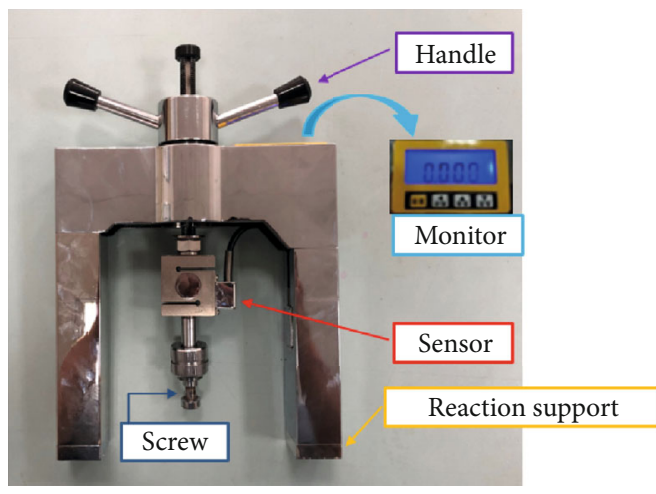

FIGURE 2: HCTC-10 coating adhesion tester.

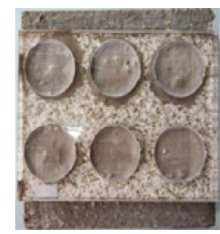

(a) Preparation of test pieces

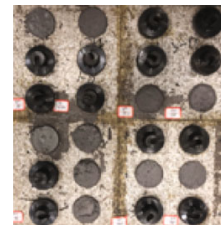

(c) Bonding pull-off unit

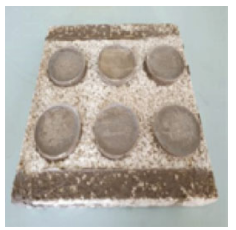

(b) Demoulding

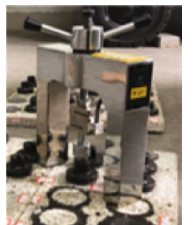

(d) Pull test
FIgURE 3: Drawing experiment steps.

spray gun. When the viscosity was below $2300 \mathrm{mPa} \cdot \mathrm{s}$, the adhesion of the slurry to the surface decreased, and the phenomenon of sag occurred. The weight of the slurry was greater than its adhesion to the surface, and the slurry sprayed from the nozzle was in the form of water mist. When the viscosity was $2300-5800 \mathrm{mPa} \cdot \mathrm{s}$, the slurry did not sag on the surface, and the TSL material was evenly distributed on the surface. The weight of the slurry was less than its adhesion to the surface so that the TSL material could be better retained on the spray surface, and the slurry sprayed from the nozzle was in

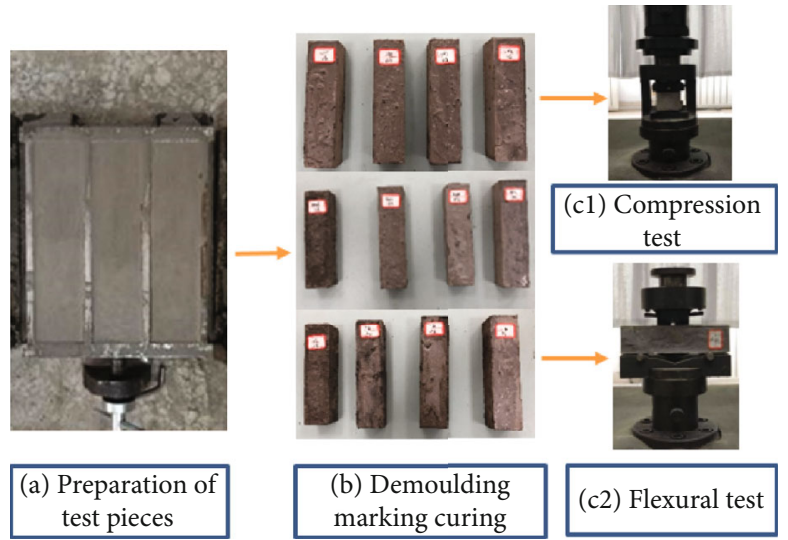

Figure 4: Compression and flexural test process.

the form of fine droplets. When the viscosity of the slurry was greater than $5800 \mathrm{mPa} \cdot \mathrm{s}$, although the slurry did not appear to sag on the surface, the slurry of the nozzle was sprayed into a filament shape, and the TSL material was sprayed onto the surface unevenly, as shown in Figure 6.

Therefore, combining Figures 5 and 6, when the viscosity was $2300-5800 \mathrm{mPa} \cdot \mathrm{s}$, the TSL material slurry had better fluidity and viscosity. The 10, 15, and $20 \%$ styrene-butadiene emulsion and the $5 \%$ pure acrylic emulsion had lower viscosity values. Although they had better sprayability, adhesion to the spray layer was poor. The $20 \%$ VAE emulsion had better adhesion but poor sprayability. Compared to the $5 \%$ styrenebutadiene emulsion, the 10,15 , and $20 \%$ pure acrylic emulsions and the 5,10, and 15\% VAE emulsions all had better sprayability.

3.2. Pull Test Analysis. Following the mixing ratios of TSL materials in Table 5 , three polymer emulsions at different polymer-cement ratios were used and tested with the HCTC-10 coating adhesion tester. All the tests were conducted on a marble surface. Because the thickness of the TSL [36-38] and the curing time [39] affect the bond strength, the TSL thickness of this test was uniformly controlled at $\sim 5 \mathrm{~mm}$, and the curing time was 7 days. After 7 days, the surface of the sample was coated with the epoxy resin glue and bonded to the pull-off unit, and the pull-out 


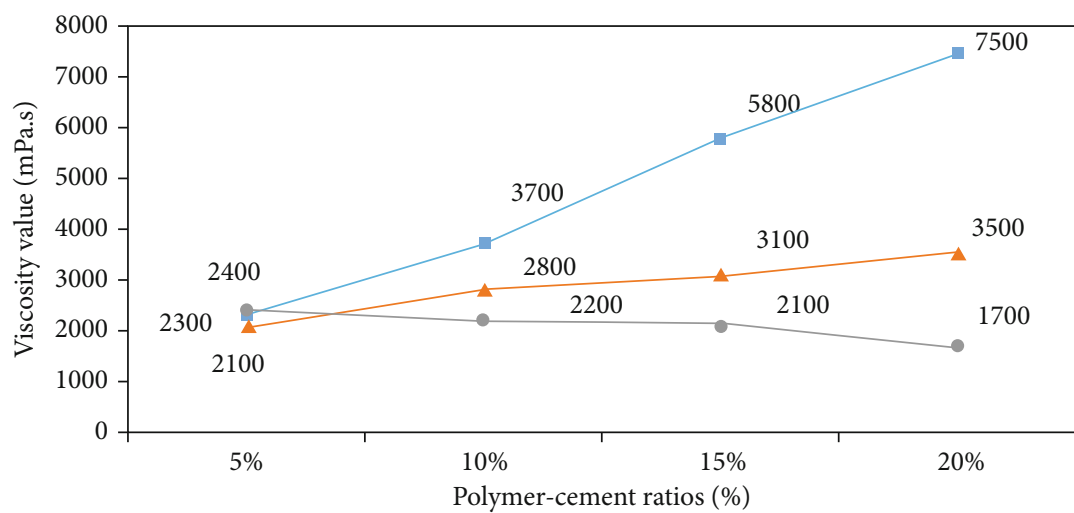

$$
\begin{aligned}
& \rightarrow \text { VAE emulsion } \\
& \rightarrow-\text { Pure acrylic emulsion } \\
& \rightarrow-\text { Styrene-butadiene emulsion }
\end{aligned}
$$

FIgURe 5: Viscosity test data.
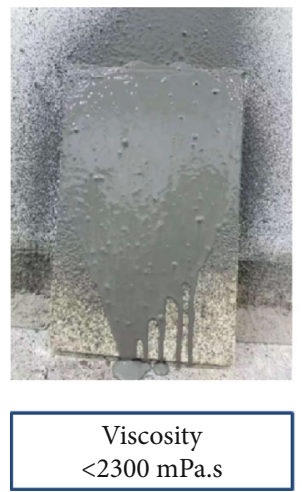
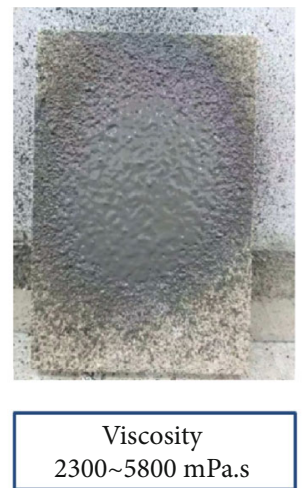
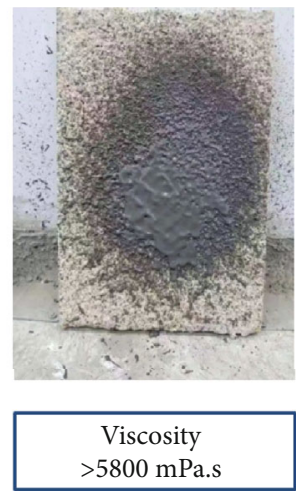

FIgURE 6: Adhesion of TSL material to the wall.

test was carried out after the epoxy resin glue solidified. The pull-out data is shown in Figure 7.

The follow observations can be made based on Figure 7:

(1) The styrene-butadiene emulsion had the largest pullout strength of $1.52 \mathrm{MPa}$ at the same ash ratio of $5 \%$

(2) The maximum pull-out strength of the pure acrylic emulsion, which occurred at a polymer-cement ratio of $10 \%$, was $1.49 \mathrm{MPa}$, was also the maximum pullout strength of the pure acrylic emulsion at the different polymer-cement ratios. The minimum pull-out strength of the styrene-butadiene emulsion was $1.19 \mathrm{MPa}$

(3) Compared to the styrene-butadiene emulsion, the VAE emulsion had the best bonding ability at a 10$20 \%$ polymer-cement ratio. The largest pull-out strength among all the test data was for the $20 \%$ VAE emulsion with a value of $2.09 \mathrm{MPa}$

(4) The growth rate of the VAE emulsion at $10-15 \%$ was faster with an increase of $63 \%$. In contrast, the growth rate of the $15-20 \%$ emulsions was relatively gentle with an increase of $7 \%$.
(5) The growth rate of the styrene-butadiene emulsion in the range of $10-20 \%$ started fast at first and then became slow

The bonding strength of the material is affected by its own bonding performance and bonding contact area, and the bonding contact area is affected by the fluidity of the slurry. With an increase of the polymer-cement ratio, the bonding strength of the VAE emulsion and the styrene-butadiene emulsion showed a trend of first decreasing and then increasing. Because the viscosity of the VAE emulsion increased with the increase of the polymer-cement ratio (see Figure 5), it was thought that the effect of the fluidity of the material on the bond strength of the material was greater than that of the material's viscosity performance when the polymer-cement ratio was $5-10 \%$. When the polymer-cement ratio was $10-20 \%$, the contact area between the material and the surface became the main factor that affected its bonding strength. When the viscosity of the material decreased, the fluidity increased, the contact area was greater, and the bonding strength of the material gradually increased.

The viscosity of the pure acrylic emulsion increased with the increase of the polymer-cement ratio (see Figure 5), and 


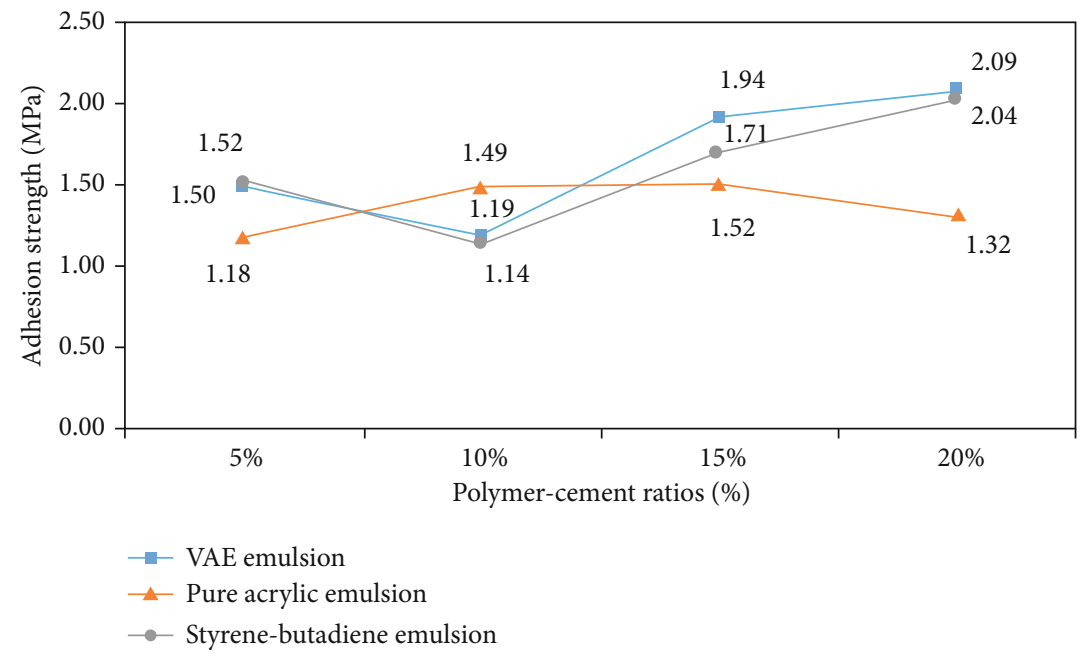

Figure 7: Pull test data.

the bonding strength showed a trend of first increasing and then decreasing. At a ratio of $5-10 \%$, the viscosity of material had the main effect on its bonding strength. At 10-20\%, the material's contact area had the largest effect on its bonding strength. In addition to considering polymer viscosity and the contact area, it is also necessary to consider whether the hydration of the cement in the polymer-modified cement matrix was complete. Figure 8 shows that when the polyacrylic ratio of the pure acrylic emulsion was $15 \%$, the material broke in the middle during the pulling process. The reason for failure due to epoxy resin is located at the interface between epoxy resin-pull-off unit or epoxy resin-thin shotcrete material. This failure mode is due to the failure of epoxy resin to interact with the surface of the pull-off unit or thin shotcrete material. Full contact, the actual contact area is small, resulting in epoxy resin bonding failure, or thin-layer shotcrete material failure occurs inside the thin-layer shotcrete material, because its bonding strength is greater than its own tensile strength [13].

3.3. Flexural and Compression Test Analysis. The specimens for the flexural and compression tests were mixed according to the ratios of TSL materials in Table 5 and made using triple test molds. After curing and demolding, a microcomputercontrolled electro-hydraulic servo universal tester was used to conduct the flexural and compression tests.

3.3.1. Flexural Test Analysis. A flexural test was performed by the microcomputer-controlled electro-hydraulic servo universal tester to obtain the destruction load data. The data shown in Figure 9 was obtained using the formula, and the following trends can be discerned:

(1) The styrene-butadiene emulsion had the maximum flexural strength of all the test groups at a polymercement ratio of $5 \%$ and then gradually decreased

(2) When the pure acrylic emulsion had a polymercement ratio of 5-10\%, the flexural strength continuously increased. At a polymer-cement ratio of $5 \%$,

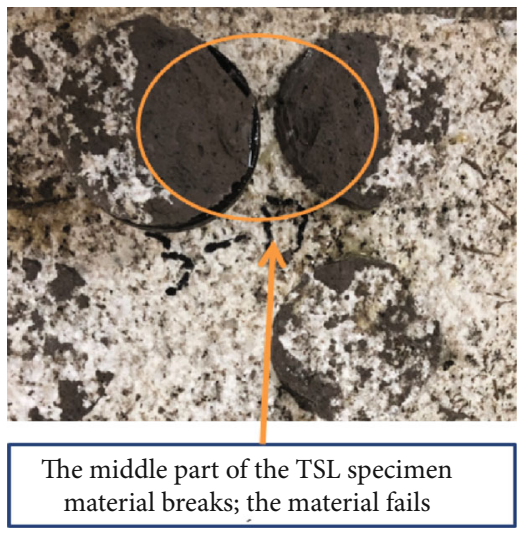

FiguRE 8: TSL material failure test piece.

the maximum flexural strength of the pure acrylic emulsion was reached with a value of $3.75 \mathrm{MPa}$, an increase of $207 \%$. When the polymer-cement ratio was 10 and $20 \%$, the flexural strength gradually decreased, with a decrease of 23 and $72 \%$, respectively. With the change of the polymer-cement ratio of the pure acrylic emulsion, the change of flexural strength was more obvious

(3) The flexural strength of the VAE emulsion continuously increased when the polymer-cement ratio was $5-15 \%$, with an increase of $159 \%$. The polymercement ratios of 10 and $15 \%$ reached the maximum flexural strength of the VAE emulsion at $4.33 \mathrm{MPa}$. When the polymer-cement ratio was $15-20 \%$, the flexural strength decreased by $13 \%$. The flexural strength of the 20\% VAE emulsion was $3.56 \mathrm{MPa}$. Compared with the other two emulsions, the flexural strength of the VAE emulsion changed more modestly when the polymer-cement ratio changed

The only selected aggregate in the sample was the light calcium carbonate, and no other coarse aggregate was added. 


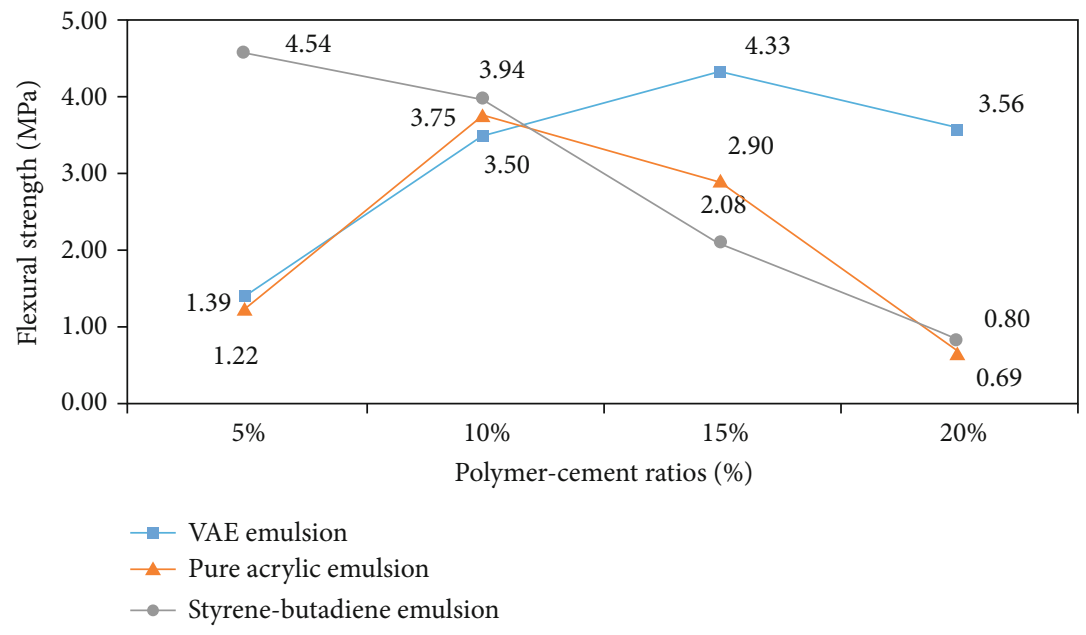

Figure 9: Flexural test data.

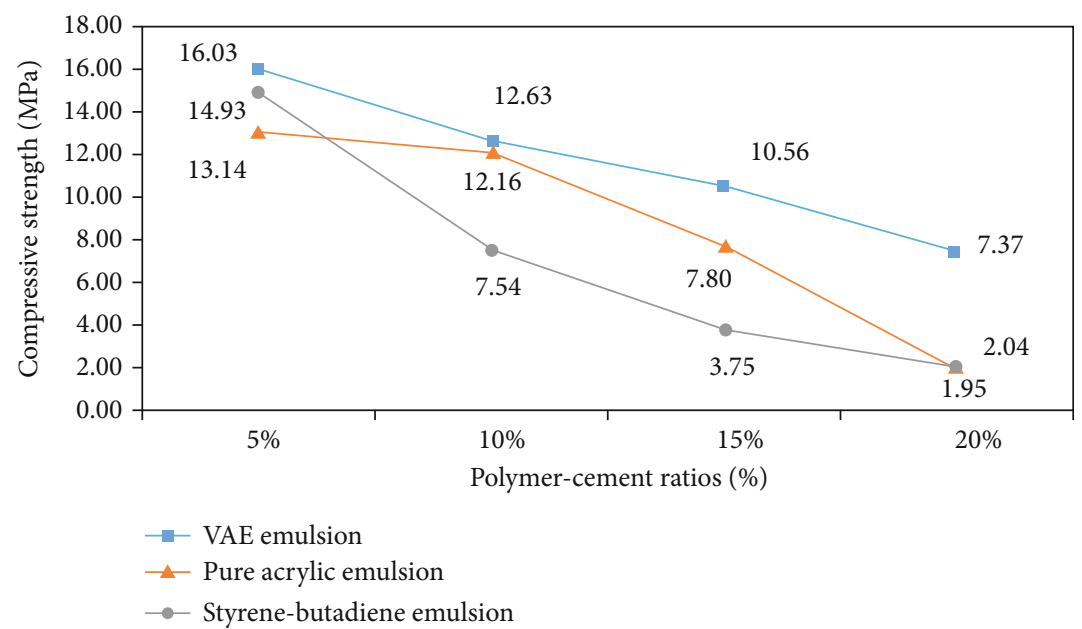

Figure 10: Compression test data.

However, the light calcium carbonate only filled the sample and improved the adhesion of the slurry to the wall surface. Light calcium carbonate as an aggregate had difficulty in improving the flexural resistance of the sample. Therefore, the main factors affecting the flexural resistance of the sample were the hydration of the cement and the adhesion and film formation of the polymer emulsion. The change of flexural strength in the three different slurries matched the Ohama model [40], which assumes that the structure of polymer network wraps the cement hardened slurry. Along with the hydration of the cement, a cement gel gradually formed, the hydration and polymer film occurred simultaneously, and the flexural strength of the VAE and pure acrylic specimens began to increase.

As the calcium hydroxide in the liquid phase reached saturation and the polymer-cement ratio increased, polymer particles were deposited on the surface of the cement particles (possibly including unhydrated cement). During the stirring process, the surface of the cement particles was covered by the polymer particles. It reduced the contact area of the cement particles with water, and it also hindered the migration of hydration products to the matrix, which slowed the hydration rate of the cement. The flexural strength of the modified specimen began to decrease with the increase of the polymer-cement ratio.

3.3.2. Compression Test Analysis. The microcomputercontrolled electro-hydraulic servo universal tester was used to perform the compression test to obtain the damage load data. The formula used to calculate the data is shown in Figure 10, which shows the following trends:

(1) The compressive strength of the three polymer emulsions decreased with the increase of the polymercement ratio

(2) Of the three polymer emulsions with polymercement ratios of 5-20\%, the maximum compressive strength of $16.03 \mathrm{MPa}$ was achieved with the VAE emulsion with a polymer-cement ratio of $5 \%$. 


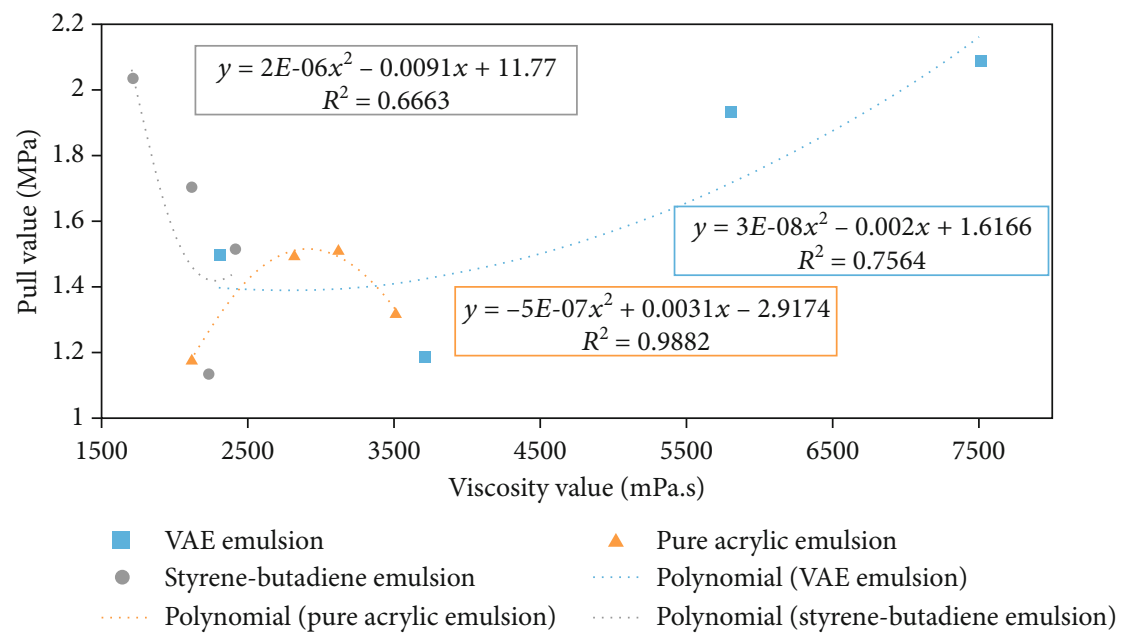

FIGURE 11: Relationship between the drawing performance and viscosity of three TSL materials.

(3) In the case of the $20 \%$ polymer-cement ratio, the VAE emulsion was 7.37 MPa, which still was notable compared to $2.04 \mathrm{MPa}$ for the pure acrylic emulsion and 1.95 $\mathrm{MPa}$ for the styrene-butadiene emulsion

The polymer in the cement paste is gradually restricted to the capillary pores, forming a polymer sealing layer on the surface of the cement particles (including unhydrated cement particles). With the increase of the polymer-cement ratio, more polymer particles are adsorbed on the surface of unhydrated cement particles. Free water that can be hydrated with the cement particles is reduced. Eventually, the unhydrated cement particles, hydration products, aggregates, and capillaries form a continuous, viscous, and spatial network structure. The aggregate is powdered lightweight concrete. There are many defects and microcracks in the spatial network structure inside the specimen. Therefore, the compressive strength of the sample will decrease with the increase of the polymer-cement ratio. The compressive specimen after load failure has good integrity and has the characteristics of a flexible material.

\subsection{Experimental Correlation Analysis}

3.4.1. Relationship between Viscosity and Mechanical Properties. Figure 11 is based on the data in Figures 5 and 7. The equation is of the pull-out strength $y$ fitted with the change of viscosity $x$ of three TSL materials with different polymer-cement ratios. The pull-out strength of the material is affected by two factors: the viscosity of the material itself and the bonding area between the material and the wall surface [41].

As the viscosity increases, the self-adhesive properties increased. However, the fluidity of the slurry on the wall surface became worse, and the bonding area was affected. It can be seen from Figure 11 that the viscosity of the VAE emulsion was the dominant factor affecting its pull-out strength. As the viscosity of the VAE emulsion increased, the pullout strength also increased. The VAE emulsion fitting equation of $R^{2}=0.7564$ had a good fit. When the viscosity of the pure acrylic emulsion increased, its pull-out strength first increased and then decreased, indicating that the pull-out strength of pure acrylic emulsion was affected by its own viscosity. After reaching the peak, as the viscosity of the pure acrylic emulsion continued to increase, the slurry fluidity gradually deteriorated, resulting in a further reduction in the contact area between the material and the wall surface. The bonding area became the leading factor affecting the pull-out strength of the pure acrylic emulsion. The pure acrylic emulsion fitting equation with $R^{2}=0.9882$ had the best fit. The pull-out strength of the styrene-butadiene emulsion first decreased and then increased with the increase of viscosity. This indicated that the pull-out strength of the styrene-butadiene emulsion was affected by the bonding area first and then affected by its own viscosity after the peak. The fitting equation of the styrene-butadiene emulsion had an $R^{2}=0.6663$, which indicated that the fit was average.

Figure 12 is based on the data in Figures 5 and 9. The equation of the change of the flexural strength $y$ and the viscosity $x$ of three TSL materials were fitted for the different polymer-cement ratios. For the VAE emulsion, as the viscosity of the slurry increased, the flexural strength first increased and then decreased. As the viscosity of the pure acrylic emulsion increased, the flexural strength also showed a trend of first increasing and then decreasing. As the viscosity of the styrene-butadiene emulsion increased, the flexural strength increased linearly. The $R^{2}$ values of the fitting equations in the three slurries with the polymer-cement ratio at VAE emulsion, pure acrylic emulsion, and styrene-butadiene emulsion were 0.996, 0.9954, and 0.8979, respectively, and had good fits. When the viscosity was low, the fluidity of the slurry was better, and the hydration of the cement was more complete. The viscosity of the polymer material and the hydration of the cement affected the flexural strength of the samples, and the flexural strength gradually increased. As the viscosity increased, the fluidity of the slurry became worse. Cement particles were wrapped by polymer emulsion particles, the interaction and motion resistance between the particles increased, and the difficulty of cement particles 


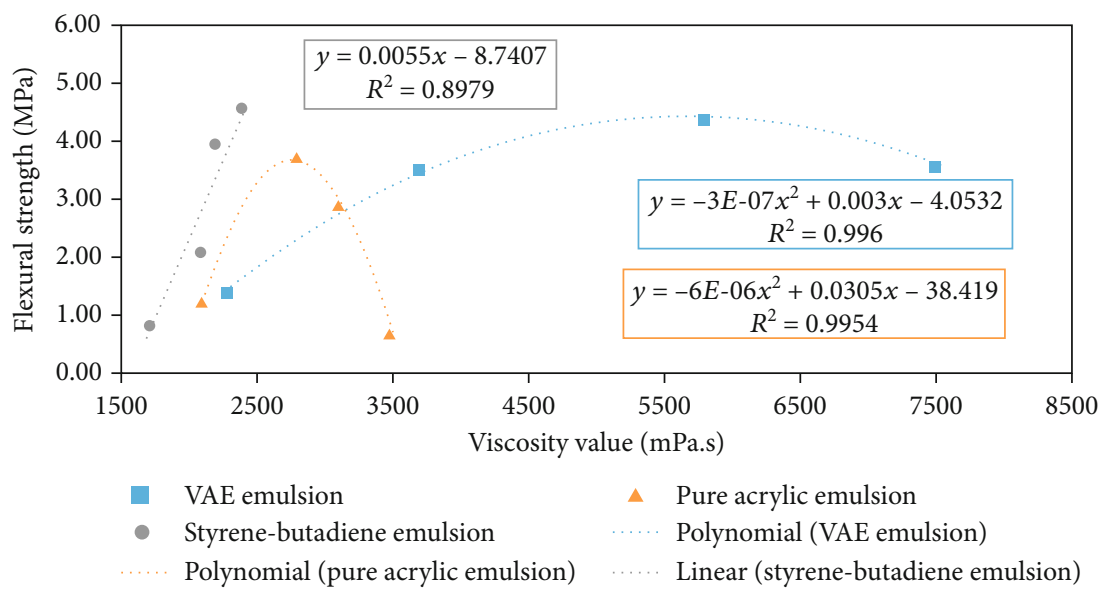

FIgURE 12: The relationship between the viscosity of three TSL materials and the flexural strength.

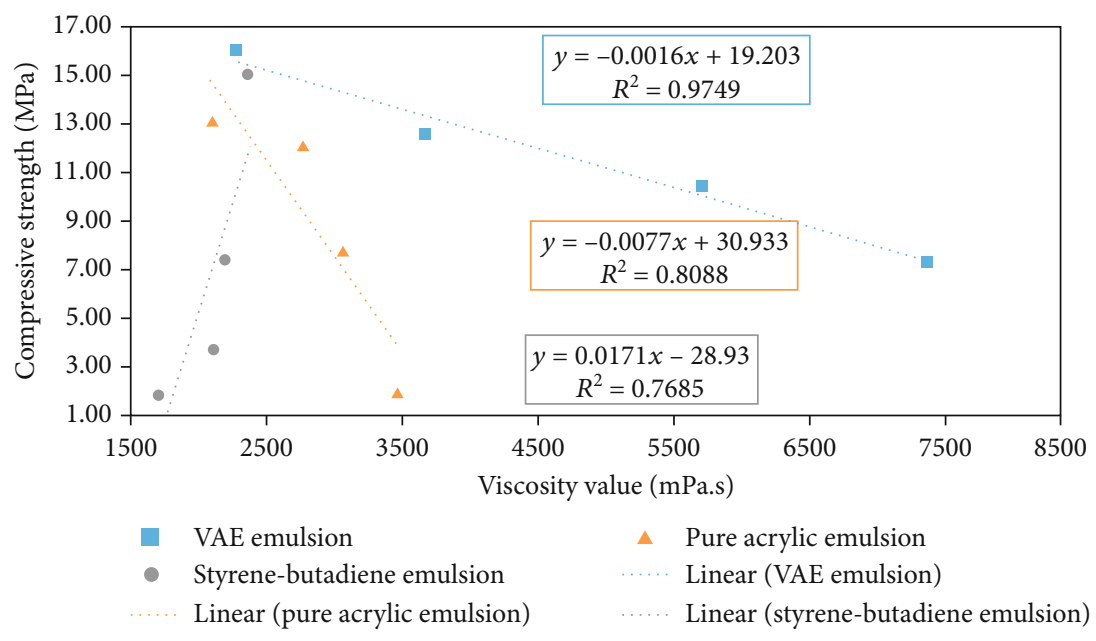

FIGURE 13: Relationship between viscosity and compressive strength of three TSL materials.

contacting free water increased, resulting in incomplete hydration of the cement and a gradual decrease in flexural strength. Combined with the experimental data, the drawing performance of the material has a low correlation with the viscosity performance.

Figure 13 is based on the data in Figures 5 and 10. The equation of the change of the compressive strength $y$ and the viscosity $x$ of three TSL materials were fitted for the different polymer-cement ratios. For the VAE and pure acrylic emulsions, as the viscosity of the slurry increased, the compressive strength decreased linearly. The styrene-butadiene emulsion increased linearly with compressive strength. The $R^{2}$ values of the fitting equations in the three slurries with the polymer-cement ratio at $\mathrm{VAE}$ emulsion, pure acrylic emulsion, and styrene-butadiene emulsion were 0.9749, 0.8088 , and 0.7685 , respectively, and the fit was generally good. At lower viscosity values, the fluidity of the slurry was better, the hydration of cement was complete, and the polymer emulsion itself had film-forming properties. The hydrated products, aggregates, and capillary pores formed a continuous, viscous, stable spatial network structure, and the sample was internally compact. Therefore, when the vis- cosity was in the range of $1500-2300 \mathrm{mPa} \cdot \mathrm{s}$, the compressive strength increased with increasing viscosity. When the viscosity was $>2300 \mathrm{mPa} \cdot \mathrm{s}$, the fluidity of the slurry decreased as the viscosity increased. The interaction and motion resistance between the particles increased, and the difficulty of cement particles contacting free water grew, resulting in incomplete hydration of the cement and the presence of unhydrated cement particles inside the samples. The density of the sample was reduced, resulting in a decrease in compressive strength as the viscosity increased.

3.4.2. Correlation Analysis of Mechanical Performance Tests. The data from the mechanical tests are presented in Figure 14, with flexural strength as the horizontal coordinate and compressive strength as the vertical coordinate. At the upper right of Figure 14 is the area with the best flexural and compressive strength properties of the sample. Based on this, the ratio of the four polymer emulsions was selected. From left to right, the corresponding polymer emulsion and ratios were VAE 10\%, pure acrylic 10\%, VAE 15\%, and butylbenzene $5 \%$. Considering only the flexural and compressive strengths, the performance of the $5 \%$ SBR emulsion was the 


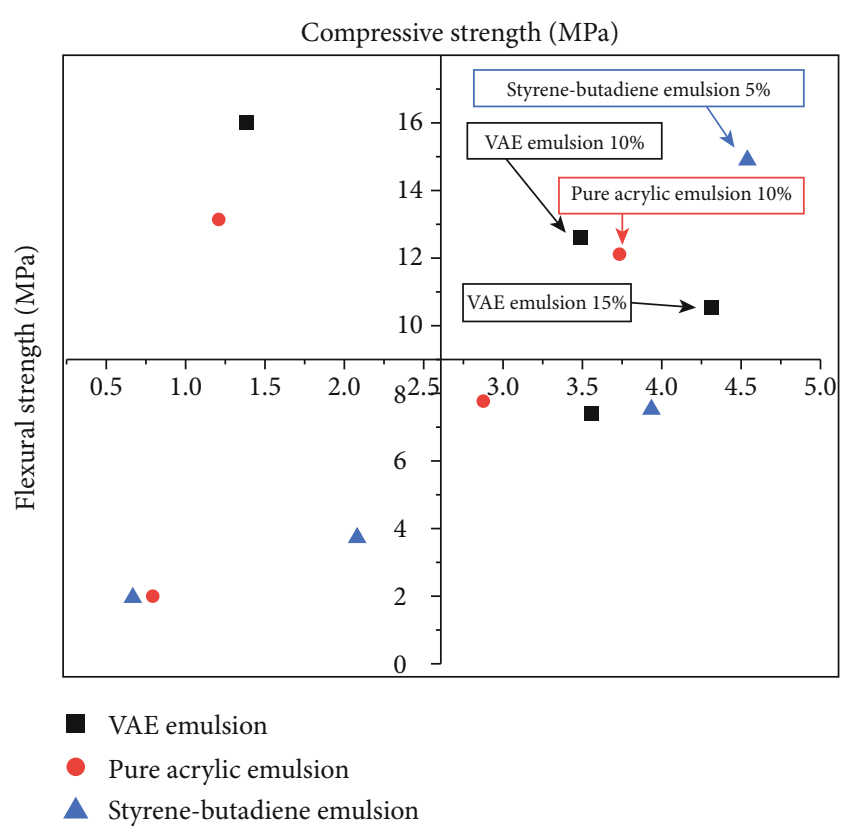

FIgURE 14: Scatter distribution of bending and compression data.

best. But compared with the other three groups, the performance of the flexural and compressive resistance did not differ notably. Without considering the test error, the maximum difference in flexural strength was $1.04 \mathrm{MPa}$, and the maximum difference in compressive strength was $4.37 \mathrm{MPa}$.

Combining Figures 5 and 6, when the viscosity value was 2300-5800 $\mathrm{mPa} \cdot \mathrm{s}$, the TSL slurry had better fluidity and viscosity. Therefore, the viscosity of $2300-5800 \mathrm{mPa} \cdot \mathrm{s}$ was taken as the horizontal coordinate, and the pull-out strength was taken as the vertical coordinate. Then, by screening out the different polymer materials with different polymer-cement ratios in the scatter plots (see Figure 15), the 15\% VAE emulsion (viscosity $5800 \mathrm{mPa} \cdot \mathrm{s}$, pull-out strength $1.94 \mathrm{MPa}$ ) could be obtained with the best wall adhesion and sprayability among the 12 different samples.

The TSL material mostly acts on the surface of the complex surrounding rock surface to solve the problem of poor fluidity and adhesion of ordinary shotcrete. Therefore, for the TSL material, we need to first consider the fluidity and bond strength of its slurry, and secondly, we consider the flexural and compressive properties of the TSL material. By using the viscosity test, pull test, flexural test, and compression test, it can be concluded that the VAE emulsion with a $15 \%$ polymer-cement ratio has good comprehensive mechanical properties and is suitable for modified polymer emulsions of TSL materials.

\section{Conclusion}

In this paper, polymer emulsions and ordinary silicate cement were used as the main raw materials, together with fillers and other additives, to prepare the samples. We used VAE, pure acrylic, and styrene-butadiene emulsions as three alternative polymers. We examined 5, 10, 15, and $20 \%$ polymer-cement ratio as variables and characterized and

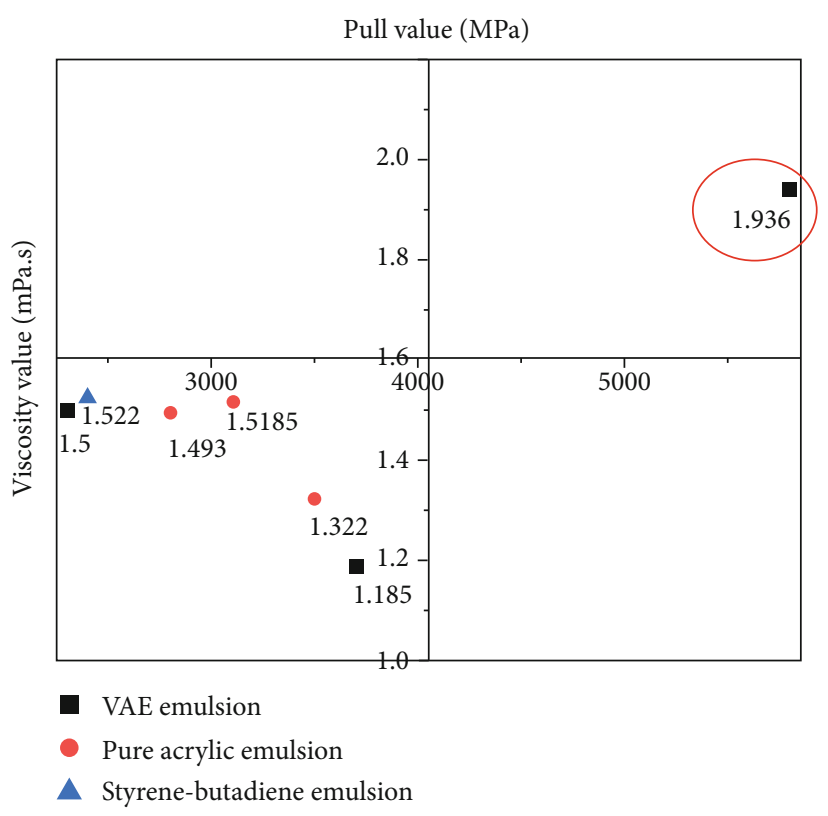

FIGURE 15: Scatter distribution of viscosity and drawing data.

analyzed them with viscosity, pull-out, flexural, and compression tests to determine that the VAE emulsion with a polymer-cement ratio of $15 \%$ had good comprehensive mechanical properties. It is suitable for modified polymer emulsions of TSL materials. The specific mechanical test conclusions are as follows.

(1) When the VAE emulsion was used to modify the cement mortar, the results showed that the VAEmodified mortar had the best viscosity performance at the same polymer-cement ratio. For the adhesion of the modified mortar on the marble surface, when the viscosity was $2300-5800 \mathrm{mPa} \cdot \mathrm{s}$, the slurry did not sag on the surface, and the TSL material was evenly distributed on the surface

(2) The viscosity of the different polymer materials and the hydration of the cement affected the flexural strength of the sample. The flexural strength of the polymer-modified mortar first increased with viscosity and then showed a significant decrease after the initial increase. For viscosity in the range of 1500$2300 \mathrm{mPa} \cdot \mathrm{s}$, the compressive strength increased with increasing viscosity. When the viscosity was $>2300 \mathrm{mPa} \cdot \mathrm{s}$, the compressive strength decreased with increasing viscosity

(3) The VAE emulsion was affected by its own viscosity, and as the viscosity increased, the pull-out strength was enhanced. The pull-out strength of the pure acrylic emulsion was first affected by its own viscosity. After reaching a peak, the bonding area became the dominant factor affecting the drawing performance. As a result, the viscosity of the pure acrylic emulsion first increased with viscosity and then decreased. The pull-out strength of the styrene- 
butadiene emulsion was at first affected by the bonding area. After the peak value was reached, it was affected by its viscosity, and the pull-out strength first decreased and then increased as the viscosity increased

(4) For the VAE emulsion, as the viscosity of the slurry increased, the flexural strength first increased and then decreased. As the viscosity of the pure acrylic emulsion increased, its flexural strength also showed a trend of first increasing and then decreasing. The folding strength increased linearly. The compressive strength of the VAE and pure acrylic emulsions decreased linearly as the viscosity of the slurry increased, and the compressive strength of the styrene-butadiene emulsion increases linearly as the viscosity increases

Future work will include a microscopic test to investigate the changes in the internal structure of the TSL material when it deforms, improve the selection and ratio of materials, and improve the overall mechanical properties of the TSL material.

\section{Data Availability}

The specific properties of the materials as listed in tables were provided by manufacturers. All data appear in the submitted article.

\section{Conflicts of Interest}

No conflict of interest exists in the submission.

\section{Authors' Contributions}

Qizheng Dong: research conception and design. Lianjun Chen: formulation of overarching research goals; funding acquisition. Weimin Cheng: data analysis; funding acquisition. Zhaoxia Liu: conducting tests and investigation process. Xiangfei Cui: data curation, original draft. Guoming Liu: design of methodology; funding acquisition. Zhenjiao Sun: investigation; verification. Zhiwei Shi: application of statistical, provision of study materials. Yaqing Zhang: data analysis such as correlation analysis of mechanical performance tests.

\section{Acknowledgments}

This study was funded by projects such as the National Key Research and Development Plan of the 13th FiveYear Period (Grant No. 2017YFC0805203), the National Natural Science Foundation of China (Grant No. 51974177, 51934004), the Natural Science Foundation of Shandong (Grant No. ZR2018ZA0602, ZR2019QEE007, ZR2019MEE115, ZR2019BG007), the Special funds for Taishan scholar project, the Shandong soft science general project (Grant No. 2019RKB01290), and the Major scientific and technological innovation projects of Shandong Province (Grant No. 2019SDZY0203).

\section{References}

[1] L. Chen, X. Zhang, and G. Liu, "Analysis of dynamic mechanical properties of sprayed fiber-reinforced concrete based on the energy conversion principle," Construction Building Materials, vol. 254, p. 119167, 2020.

[2] X. Cui, G. Liu, C.-L. Wang, and Y. Qi, "Effects of PET fibers on pumpability, shootability, and mechanical properties of wetmix shotcrete," Advances in Civil Engineering, vol. 2019, Article ID 2756489, 14 pages, 2019.

[3] G. Liu, W. Cheng, L. Chen, G. Pan, and Z. Liu, "Rheological properties of fresh concrete and its application on shotcrete," Construction Building Materials, vol. 243, p. 118180, 2020.

[4] G. Liu, X. Guo, W. Cheng, L. Chen, and X. Cui, "Investigating the migration law of aggregates during concrete flowing in pipe," Construction Building Materials, vol. 251, p. 119065, 2020.

[5] Q. Liu, J. Chai, S. Chen, D. Zhang, Q. Yuan, and S. Wang, "Monitoring and correction of the stress in an anchor bolt based on Pulse Pre-Pumped Brillouin Optical Time Domain Analysis," Energy Science \& Engineering, vol. 8, no. 6, pp. 2011-2023, 2020.

[6] L. Chen, P. Li, G. Liu, W. Cheng, and Z. Liu, "Development of cement dust suppression technology during shotcrete in mine of China-a review," Journal of Loss Prevention in the Process Industries, vol. 55, pp. 232-242, 2018.

[7] L. Chen, G. Ma, G. Liu, and Z. Liu, "Effect of pumping and spraying processes on the rheological properties and air content of wet-mix shotcrete with various admixtures," Construction Building Materials, vol. 225, pp. 311-323, 2019.

[8] W. Cheng, G. Liu, and L. J. A. S. Chen, "Pet fiber reinforced wet-mix shotcrete with walnut shell as replaced aggregate," Applied Sciences, vol. 7, p. 345, 2017.

[9] P. Li, Z. Zhou, L. Chen, G. Liu, and W. Xiao, "Research on dust suppression technology of shotcrete based on new spray equipment and process optimization," Advances in Civil Engineering, vol. 2019, Article ID 4831215, 11 pages, 2019.

[10] G. Liu, L. Chen, W. Cheng, and Y. Huang, "Research on pump primers for friction reduction of wet-mix shotcrete based on precreating lubricating layer," Advances in Materials Science and Engineering, vol. 2017, Article ID 3462074, 12 pages, 2017.

[11] G. Pan, P. Li, L. Chen, and G. Liu, "A study of the effect of rheological properties of fresh concrete on shotcrete-rebound based on different additive components," Construction Building Materials, vol. 224, pp. 1069-1080, 2019.

[12] H. Ozturk and D. Guner, "Failure analysis of thin spray-on liner coated rock cores," Engineering Failure Analysis, vol. 79, pp. 25-33, 2017.

[13] L. Chen, Z. Zhou, G. Liu, X. Cui, Q. Dong, and H. Cao, "Effects of substrate materials and liner thickness on the adhesive strength of the novel thin spray-on liner," Advances in Mechanical Engineering, vol. 12, 2020.

[14] K. P. Großkurth and A. J. B. S. Konietzko, "Polymerbewirktes Zug- und Druck-Tragverhalten in zementgebundenen Betonen (PCC)," Beton-und Stahlbetonbau, vol. 84, no. 9, pp. 217-222, 1989.

[15] Y. Ohama, Handbook of polymer-modified concrete and mortars: properties and process technology, William Andrew, 1995.

[16] L. Bureau, A. Alliche, P. Pilvin, and S. Pascal, "Mechanical characterization of a styrene-butadiene modified mortar," 
Materials Science Engineering: A, vol. 308, no. 1-2, pp. 233240, 2001.

[17] X. Li, M. Jiang, and H. Jin, "Study on performance of pure acrylic emulsion waterproof repair mortar," Low Temperature Architecture Technology, vol. 38, pp. 21-22, 2016.

[18] M. Xu and H. Pan, "Experimental study on the effect of VAE latex powder on the mechanical properties of cement repair mortar," Wall Material Innovation \& Energy Saving in Buildings, pp. 61-64, 2014.

[19] D. Guner and H. Ozturk, "Experimental and numerical analysis of the effects of curing time on tensile mechanical properties of thin spray-on liners," Rock mechanics rock engineering, vol. 49, no. 8, pp. 3205-3222, 2016.

[20] S. Espley, D. Tannant, G. Baiden, and P. Kaiser, "Design criteria for thin spray-on membrane support for underground hardrock mining," in Canadian Ins. Of Mining and Metallurgy Annual Meeting, Calgary, 1999.

[21] J. F. Archibald and D. O. DeGagné, "Recent Canadian advances in the application of spray-on polymeric linings," in Mining Health and Safety Conference, Vancouver, Canada, 2000.

[22] S. Gilbert, S. Saydam, and R. Mitra, "Laboratory investigation of the potential use of thin spray-on liners in underground coal mines," in Proceedings of the symposium of extracting the science: a century of mining research, pp. 225-234, Sydney, Australia, 2010.

[23] V. Lau, S. Saydam, Y. Cai, and R. Mitra, "Laboratory investigation of support mechanism for thin spray-on liners," in Proceedings of the 12th International Conference of International Association for Computer Methods and Advances in Geomechanics (IACMAG), pp. 1381-1388, Goa, India, Citeseer, 2008.

[24] Z. C. Li, R. Mitra, S. Saydam, and D. Chalmers, "Experimental study on support mechanism of thin spray-on liners in underground coal mines," in 3rd ISRM Young Scholars Symposium on Rock Mechanics, International Society for Rock Mechanics and Rock Engineering, Xi'an, China, 2014.

[25] E. Morton, A. Thompson, and E. Villaescusa, "Static testing of shotcrete and membranes for mining applications," in Proceedings of the 6th International Conference on Ground Support, pp. 195-212, Sydney, Australia, 2008.

[26] Q. Qiao, J. Nemcik, I. Porter, and E. Baafi, "Laboratory investigation of support mechanism of thin spray-on liner for pillar reinforcement," Géotechnique Letters, vol. 4, no. 4, pp. 317321, 2014.

[27] H. Yilmaz, "Tensile strength testing of thin spray-on liner products (TSLs) and shotcrete," Journal of the Southern African Institute of Mining and Metallurgy, vol. 110, pp. 559$569,2010$.

[28] M. Son, "Adhesion strength at the shotcrete-rock contact in rock tunneling," Rock Mechanics and Rock Engineering, vol. 46, no. 5, pp. 1237-1246, 2013.

[29] H. Ozturk and D. D. Tannant, "Influence of rock properties and environmental conditions on thin spray-on liner adhesive bond," International Journal of Rock Mechanics and Mining Sciences, vol. 48, no. 7, pp. 1196-1198, 2011.

[30] L. Chen, Research of Flexible Cement Base Thin Layer Repairing Material, Wuhan University Of Technology, Wuhan, China, 2015.

[31] H. Wang, The nano-materials modified polymer/sulphoaluminate cement composite coatings, University Of Jinan, Jinan, China, 2018.
[32] W. Zhao, Properties and microstructure of PB-g-PS latexmodified cement mortars, Northeastern University, Shenyang, China, 2010.

[33] H. Guo and X. Hang, "Research about polymer repair mortar materials by using spraying," New Building Materials, vol. 43, pp. 70-73, 2016.

[34] L. Fengwen, Z. Shaobo, and W. Jiansheng, "Trial on thin spray-on liner support at Donghuantuo coal mine," Coal Mine Blasting, pp. 6-9, 2018.

[35] J. Nong, Study on Bonding Performance of Polymer-Modified Cement-Based Bonding Composite, Hunan University, Changsha, China, 2014.

[36] K. Kendall, "The adhesion and surface energy of elastic solids," Journal of Physics D: Applied Physics, vol. 4, no. 8, pp. 11861195, 1971.

[37] H. Ozturk and D. D. Tannant, "Thin spray-on liner adhesive strength test method and effect of liner thickness on adhesion," International Journal of Rock Mechanics and Mining Sciences, vol. 47, no. 5, pp. 808-815, 2010.

[38] F. Yang and J. C. M. Li, "Adhesion of a rigid punch to an incompressible elastic film," Langmuir, vol. 17, no. 21, pp. 6524-6529, 2001.

[39] Z. Li, S. Saydam, R. Mitra, and D. Chalmers, "Investigation on adhesion strength of thin spray-on liners in an underground coal mine," in 2015 Coal Operators' Conference, Taiyuan, China, 2015.

[40] C. Beyler, "Toxicity assessment of products of combustion of flexible polyurethane foam," Fire Safety Science, vol. 26, pp. 476-484, 2007.

[41] N. Opedal, J. Todorovic, M. Torsaeter, T. Vralstad, and W. Mushtaq, "Experimental study on the cement-formation bonding.," in SPE International Symposium and Exhibition on Formation Damage Control, Society of Petroleum Engineers, Lafayette, LA, USA, 2014. 